\title{
CLOUD COMPUTING STRATEGY AND ADOPTION IN HIGHER EDUCATION: THE CASE OF SAUDI ARABIA
}

\author{
Hamad Balhareth \\ College of Business Administration/ University of Haeil, Hae il, P.O.Box: 2440, KSA
}

\begin{abstract}
In today's environment, information technology is constantly evolving and getting updated to meet the fast pace of the world. The impact of this rapid development can be felt across the organization as a whole, in both public and private sectors. One such technology, which has taken the world by storm is cloud computing. Cloud computing has emerged as a vital platform as is playing a pivotal role in defining IT strategies. Cloud computing can help public and private organizations to improve the efficiency of business processes, reduce the footprint of IT operations, and improve overall profitability and business success. The application of cloud computing service is the fastest means of revolutionizing an organization's IT. It offers the benefits of reduced cost, increased flexibility, structural agility, and scalability, based on both the size and growth of the related business.

The current study focuses on the scope of future implementation of cloud computing services at Saudi Arabian universities. Cloud computing has the potential to rapidly accelerate the trajectory of modernization of the educational system of Saudi Arabia. Through the application of cloud computing technology, IT department can handle high volume of data and manage the university's maintenance needs as well as technical growth. Cloud computing also enables IT department to effectively manage various educational systems like labs, research facilities, computer learning systems, libraries, etc. Cloud computing can help the University to reduce its budget expenses and decrease the total number of computer licenses required. The various departments of the University can also easily access various educational resources by using cloud computing. So, developing countries like Saudi Arabia should embrace the cloud computing to share resources and reduce expenditures. This will help to promote collaboration among the Saudi Universities and can improve the nation's ability to generate proficient research.
\end{abstract}

Keywords: Information Systems; Saudi Arabia, Universities; Cloud Computing; University Resource Management, Restructuring Higher Education. 
Cite this Article: Hamad Balhareth, Cloud Computing Strategy and Adoption in Higher Education: The Case of Saudi Arabia. International Journal of Information Technology \& Management Information System 9(1), 2018, pp. 30-38. http://iaeme.com/Home/issue/IJITMIS?Volume=9\&Issue $=1$

\section{INTRODUCTION}

Internationally, universities are facing intense pressure to use Information Technology (IT) to enhance their efficiency, increase faculty job satisfaction, improve student experiences, and manage day to day operations. The interests of university stakeholders, such as students, parents, teachers, employees, and administration, must be considered when trying to measure the impact of any new technology on the University environment. They are equally involved in the educational planning process, and are responsible for the growth and execution of various campus activities. With the growth of technology as a whole, the universities have been forced to modernize campuses. This has led to a growth in demand for data. Also, the demand for high quality of information, data collection, processing, storage, planning and management of campus activities has increased. In order to meet the demands and expectation of stakeholders, the universities must adopt storage and computing system that integrates multiple services and manages concerned requests. Presently, such kinds of systems are limited. Also, the universities of Saudi Arabia face several challenges related to resource management. At the same time, the numbers of students have rapidly increased (Alamri, 2011).

Over the years, Saudi Universities have been actively expanding the adoption and execution of information technology applications. The implementation of network information storage systems by Saudi Universities has been a prominent element for the modernization of the technology infrastructure. This has enabled the universities to meet data storage demands. They are able to centrally locate data generated by all of its offices. Such data includes student information, faculty information, financial records, research related data etc. However, implementation and expansion of the use of cloud computing services requires technically competent human resources. Also, universities need to allocate sufficient budgetary resources required for implementing cloud computing.

It has been found that private educational institutions have taken the lead in use of IT and data storage. As these institutions have increasingly migrated data storage to the cloud, it has enhanced their individual ability to provide a collaborative learning environment and expanded their research capabilities. It has enhanced their ability to cut IT costs and provide higher levels of computing service to those within their network. This strategy is important for all Universities because of the need manage budgets and bring down overhead costs.

One area in which IT is especially important is University laboratories (Dikaiakos et al, 2009). These laboratories are responsible for the conducting experiments and research. Each lab must be paired with an IT administrator, who works with all of the lab locations at the university, and provides related technology and services associated with the labs. This administrator is responsible for creating and enforcing rules related to the use of the cloud computing system. He is responsible for controlling who has access to files, what type of files they can access, and whether or not the files can be edited or altered. This has compelled the university administration to analyze the most efficient way to gain access to secure, affordable, and dependable computing services.

Cloud computing is an automated, scalable and virtualized development platform that has the potential to provide services on demand to customers over the internet/network by deploying hardware and software resources (Singh et al., 2013). Due to the benefits and potential of cloud computing, the researcher is seeking to determine the scope of cloud 
computing implementation in the universities of Saudi Arabia. The Government of Saudi Arabia has actively constructed a Digital Government Services Maturity Index (Yessr Report, 2017). It is an assessment tool for determining the performance of digital services and the development of IT structures within government services provided to the public. This tool encourages government agencies to actively evaluate their services, to review their current IT infrastructure, to determine if it is mature, or needs further development. The goal of this process is to increase the number of public institutions with mature, state-of-the art digital services. This increases the quality of services provided by the government. This promotes social well-being by encouraging policy-centric development. This also provides increased support for the factors that impact individual institution's ability to meet the standards established by the government for the provision of services. Unfortunately, analysis demonstrates that higher education is significantly lagging in the construction of mature digital services (Deloitte, 2017). Currently, the university achievement range is $61 \%$ in the low range, $9 \%$ in the medium range, and only $30 \%$ in the implementation and access to integrated educational services. This means that universities are failing to meet the key performance markers established in the National Transition Plan 2020, which established range of $85 \%$ for all government agencies (Yessr Report, 2017).

Thus, it is a critical time for Saudi Arabian universities to actively address implementation of cloud computing. It will help them to meet the national goals and enhance computing and data storage, in accordance with the standards established in the Digital Government Services Maturity Index. Bearing these end goals in mind, the paper discusses the best approach to successfully deploy cloud computing across the higher education industry.

\subsection{Restructuring Higher Education in Saudi Arabia}

Saudi Arabian Universities are overseen by The Ministry of Higher Education. The ministry was established in 1975, separating the management of tertiary education from that of primary and secondary education. The ministry manages not only the oversight of institutions of higher education, but also educational offices, scholarship, and building relationships with international academic entities. Currently, there are 25 public universities and eight private universities in Saudi Arabia (Urrahman and Alhaisoni, 2013). The public universities are connected to and overseen by the Ministry of Higher Education, and receive some degree of public funding. They also have a degree of independence, as it relates to their academic focus, scope of studies, and administrative concerns (Alrashidi \& Phan, 2015). For example, each university is responsible for creating its own curriculum, degree plans, and is accountable for the hiring and firing of faculty and staff. Like many other nations in the region, Saudi Arabia's tertiary education system is quite young. Approximately $65 \%$ of federally funded universities were only established in the last 15 years. The oldest and largest university is King Saud University in Riyadh. It was founded in 1957. It currently has capacity for between 60 and 65 thousand students and seeks further expansion (Ministry of Higher Education, 2014). The current availability of governmental educational institutions capacity is insufficient to educate the number of students seeking to study in the universities.

The rapid growth of the demand for higher education. The increasing cost of both providing that education and attending universities has posed a significant financial burden for the Saudi Arabian government. This has led the government to consider restructuring educational structure in order to increase efficiency. Some countries have restructured their educational system by increasing privatization of universities. This is because as educational systems grow, they also become more bureaucratic and require a greater amount of regulation. Greater regulation ensures that the education provided is high-quality and appropriate to the goals of the nation and the betterment of students. Accreditation, overseen by the national 
government, must be established to hold the corporate universities, or privatized educational institutions to a greater public accountability and increased transparency, as it relates to their individual performance (Lee et al. 2017).

A cloud based audit management system increases the overall productivity of University Audit. It creates an integrated and fully paperless system for the management of the internal auditing features. These systems typically include a risk database, project management tools including scheduling and time-keeping, and web-based recommendation systems for the organization as a whole.

\section{THE NEXT GENERATION OF COMPUTING}

The current cloud computing platform is the fifth generation of cloud technologies and has a number of advanced features including: mainframe, personal computer, client server computing and web (Rajan and Jairath, 2011). At the most fundamental level, the cloud computing service is a construct that allows users to access all applications regardless of location. The data and applications themselves reside in a location outside of the computers connected device network. Typically, data is actually stored at a distant datacenter. This allows viewers, including all university stakeholders like faculty and students, to access information and use applications from any site with internet access. The National Institute of Standards and Technology (NIST) more specifically defines cloud computing as "a digital model for enabling on demand network access to a shared pool of configurable computing resources that can be rapidly provisioned and released with minimal management efforts or service provider interaction." (Mell and Grance, 2011). Cloud computing is, therefore, a more general term of computing that involves delivering hosted service over the internet to multiple sites. The benefit of this system is that another company hosts the application and data. It also manages the costs of servers, software updates and expansion of data storage. On the basis of the contracts for the cloud service, one will pay less for services than if they self-host. However, all the users will collectively pay more than the cost, allowing the hosting company to profit, overall.

Cloud computing has several characteristics that are of specific benefit to subscribers. It has the illusion of availability of infinite storage space, data, and application, in and on demand environment. The on-demand environment provides a self-sufficient service. It eliminates the demand for the cloud user to plan ahead for such issues. The cloud's ubiquitous network access enables the subscriber to access resources from any location via internet. The cloud is a location independent resource which offers additional benefits like greater data security and increased accessibility. It offers rapid elasticity, pay-per use for short term use, reduced overall cost, reduced demand for skilled labor, and improved capital utilization. It can reduce the cost and demand for skilled labor by as much as $50 \%$. Such reduction can be achieved by simplification of configuration, operations, management and monitoring. It can also improve capital utilization by as much as $75 \%$.This will help to reduce licensing cost and provision cycle time ((Bhanti et al., 2011).

Furthermore, the public cloud computing model for service delivery is different than the private cloud in several ways. Public cloud has a greater level of abstraction and allows exportation to cloud users with a lower level of overall computing resource management. The cloud delivery models can be divided into three basic categories: infrastructure as a service (IaaS), platform as a service (PaaS) and storage as a service (SaaS) systems. IaaS is a cloud service that offers computations resources, including servers, networks, and storage, based on a shared facility management approach. It is overseen by the provider of the cloud on an ondemand basis. PaaS uses the cloud as an export application development platform for a specific class of applications. SaaS provides a cloud storage platform that stores data on a 
shared server rather than within the local system. This is a means of allowing a large third party service to rent out storage space on their system to end users. They can retrieve their data from any internet connection. This reduces the need for IT in an organization because maintenance of storage is managed by off-site cloud professionals. Implementation of these cloud computing models is an ideal solution to the various issues of Saudi Arabian universities as it relates to the modernization and maturation of their digital service models.

\section{ROADMAP FOR CLOUD COMPUTING}

All of the previously detailed forms of cloud services are commonly used among small to medium sized businesses. They can be implemented within Saudi Arabian universities. The universities do not need to purchase and maintain a large storage server, if they deploy a cloud computing SaaS platform. In this model, storage is simply rented from a provider, using a cost-per-data stored or cost-per-data-transferred payment model. The university's budget does not have to accommodate the expanding need for larger and more complex servers. Instead the universities simply pay for the data actually used or needed. This is more flexible, scalable and affordable in the long term. This is even more relevant when the universities continue to grow. Cloud computing makes it easy to manage complexities, provide backup replication, disaster recovery etc. This reduces the burden on stakeholders as well, because files are better protected against accidental deletion, corruption, or other similar issues. It also protects the research and key student data should a disaster occur, including natural calamities, fires, or other catastrophic disasters. Back-up data are no longer subject to the devastation of these events. So cloud storage provides an extra level of integrity and protection for all of the university's data.

At the most basic level, the cloud storage provider must employ combination of approaches that provide both access and moving security. These include encryption techniques, like an encoding algorithm, an authentication process, and authorization practices. The cloud also supports efforts to decrease the college's ecological footprint by helping them go green. Since, the documents are both consolidated and digitized; so this reduces paper use, power consumption, and minimizes pollution. There are seemingly endless benefits regarding implementation of cloud computing. In Saudi universities. However, it is also important to consider the various risk factors that are involved with cloud computing implementation.

\subsection{Benefits and Risks of using Cloud computing}

Any time a public entity, or government institution implement a cloud computing model they stand to benefit. Cloud computing enables the concentration and centralization of data, and software resources. This improves the overall consistency, dependability and accuracy of the system (Zissis and Lekkas, 2011). This is because centralization of data and applications increases the total organizational capacity to provide access to diverse tools. This enhances communication between stakeholders, provides greater control over the data and the streamlines the system. It also reduces the time required to gain access to data and software applications, between individual users and collaborating organizations. This creates a situation in which existing remote infrastructure can be leveraged to maximize the use of common information systems; reduce the installation, monitoring, and related expenses; and focus on improving the overall quality of services rendered (Chhetri et al. 2015). The central management, development, implementation, and assessment of the system can then be amortized across the federal structure. This helps to reduce the burden on individual institutions.

However, there are risks involved in cloud computing that must be managed. Because of the sheer size, complexity, and novelty of the network, there are a number of uncertainties and 
valid concerns regarding the maturity and applications of cloud computing. The primary areas of concern include service provider lock-in, performance, latency, provider trust, privacy, security, and reliability (Sultan, 2014). One of the primary concerns is to make sure that only those with clearance or authorization can gain access to specific set of data. This is because typically cloud computing provides universal access to stored data for all stakeholders involved. The opportunities for greater collaboration via cloud computing also pose an inherent risk because security of data can be compromised. (Trkman \& Desouza, 2012). This is closely connected to the issue of lack-of-trust among various parties involved in cloud computing (Armbrust et al. 2010). So, organizations have to question the applications of cloud computing and its capabilities. There are doubts on trustworthiness of cloud computing platform and organization's ability to protect sensitive data. Such doubts are partly due to loss of control over data, lack of transparency around security practices, and the vague security assurances provided by cloud service providers (ibid). Thus, it is important that universities must research the security implications of cloud computing and track long term implications of its impact on data security (Luftman and Ben-Zvi 2011).

In the present time, Government organizations are under pressure to ensure that their IT investments provide value for money and improve their business performance (Xu 2012). Those in favor of the deployment of cloud technologies argue that its implementation decreases enough cost in spite of the related risks. Existing literature and related research, including the works of both Wyld (2009) and Sultan (2014) nonetheless highlight relevant risks that must be considered while deploying cloud computing. It is important to develop a holistic approach while deploying cloud computing. It is critical for decision makers to learn about the impact of Information Systems on the organization as a whole. This knowledge should be used to improve organizational performance. Related risks and rewards related to deployment of digital infrastructure should also be considered (Irani and Love 2008).

The theoretical models mostly focus on the science of the cloud computing (Marinescu2013). The existing theories such as IT diffusion and Technology Acceptance Model (Legris et al.2003) are most germane to understand the use of cloud computing. However, it is also important to understand the centralization and current use of cloud based services.

\subsection{The Need for Central Higher Education Cloud Computing}

Internationally, several countries (like US, UK, European Union, Australia, Singapore etc.) are trying to eliminate redundancy, increase flexibility and provide greater access to technology at a lower cost. They view cloud services as a means for improving the delivery of higher education to stakeholders. The Saudi Arabian government has already implemented a number of ICT initiatives under the umbrella of the National e-Government Action Plan. This includes the creation of ICT infrastructures both at the center and city levels.

The infrastructure of higher education must be able to provide a general framework or set of guidelines for implementation of cloud computing in the universities. The primary goal should be to maximize the usefulness of the existing infrastructure, use applications across variety of organizational niches and increase efficiency of service delivery to all stakeholders in the educational sector. This in turn would support the goal of improving the higher educational infrastructure and help to achieve goals of the Saudi Vision 2030. So it is necessary that IT Department of the Saudi Ministry of Education should embark on the project of 'HE Cloud'. The 'HE Cloud' projects enable the development of a central cloud computing environment. It will be used by higher educational institutions and technical colleges at the center and city levels. It will enable the ministry of Education to leverage cloud computing for effective delivery of e-services. Also, the Saudi government will be able to 
create and provide cloud applications for educational institutions of the country as a whole. Such a pan-country education cloud environment can serve as a shared source of cloud-based infrastructure resources, data and other applications. In addition, such a cloud based environment would be easy to access and its resources can be seamlessly shared across the network of universities as a whole.

\subsection{The Key Drivers and Potential Benefits of Higher Education Cloud}

The Ministry of Education need to invest in building up base ICT infrastructure for cloud computing. This process can be started by building upon the current ICT infrastructure. Cloud computing can enable optimum utilization of the ICT infrastructure and help to reduce the wasteful expenses. This can help develop applications that can be shared across educational institutions with the help of Higher Education Cloud Appstore. Customized applications can be developed by all Universities across the nation and they can be shared with other institutions. Thus, Universities will have more liberty to decide allocation of resources. They can channelize their energy to further promote their core objectives like improving programs, developing research etc. They can allocate resources where they are mostly needed.

The higher education cloud can enable integrated visibility and free sharing of resources across institutions. So, the universities do not need to invest resources for developing complex ICT infrastructure, which has historically proven to be complex and challenging. The infrastructural and software resources can be organized within the common HE cloud platform. This platform can capitalize on the virtual infrastructure and organization of the cloud system. The scalability of HE cloud system can allow the institutions to meet immediate needs. Such system is particularly useful for applications where there is a burst of demand for ICT resources at regular intervals.

The HE cloud can help the universities to meet budgetary challenges by promoting resource sharing in an economically efficient manner. At the same time, it can enable the universities to meet their objectives effectively. The universities can provide new services to stakeholders faster than they are being delivered via traditional methods. Quick and easy access to ICT resources will enable universities to provide academic services to all stakeholders at a rapid pace.

At the same time, the universities need to ensure security of cloud services. Robust security framework for the HE cloud would result in less complex and more secure data environment. This will assist in the creation of fully integrated set of resources and provide interoperability across the entire cloud.

The pay-per-use pricing model of cloud computing allows for the creation of ICT applications and digital resources that can be used by all members of the network. There is no need to purchase ICT infrastructure which can be shared via the cloud Also, there are lower maintenance expenses. Software as a services are easier to procure within this environment. This provides a unique opportunity to the educational institutions. They can automate easily without having to develop services through the lengthy cycle for acquiring new technology. Also, majority of cloud offerings are generated on the foundation of a prebuilt standardized solution. The HE Cloud can minimize the Ministry of Education's efforts in managing the resources and IT. Simplified technology resources will guarantee easy availability of new upgrades. It will also ensure that IT resource requests are fulfilled in a timely manner.

Cloud computing will enable increased mobility and collaboration by sharing data, applications and software storage within the cloud. Also cloud provides anytime and anywhere availability. Also, universities need to provide services that are reliable, portable, private and secure. This helps them to build citizen-confidence and inspire trust in education 
services. So, the cloud should prescribe the standards about integration, interoperability, data security, information privacy, portability and ease of access.

\section{CONCLUSION}

This article has demonstrated that the implementation of cloud technology for Saudi Arabian universities holds great promise. The technology of cloud computing has already been proven to be highly beneficial at the corporate or business level. So, it is recommended for implementation in Saudi universities on a larger scale.

Cloud computing allows virtualization and the separation of hardware and software in the data storage process. This would help to meet the needs of developing countries like Saudi Arabia with severe budgetary restrictions. This would allow the universities to pool resources and reduce the cost of infrastructure. Also, this would provide a centralized storage system, increased storage space, faster processing and greater bandwidth to all universities. This in turn, will allow the universities to become more efficient. It would also allow the universities to pool their resources, reduce the cost of software licensing and increase total operating expenses. So, the administration of all universities needs to work alongside the Ministry of Education to develop a higher education cloud for Saudi universities. At the same time, the universities need to work on improving security of cloud computing services. In spite of the risks, it can be argued that cloud computing provides far greater benefits. Furthermore, cloud computing services can facilitate inter-organizational collaborations on a greater level. So, it will provide ease of access to all stakeholders and enhance the research level of the nation.

\section{REFERENCES}

1. Alamri, M. (2011). Higher education in Saudi Arabia. Journal of Higher Education Theory and Practice, 11(4), 88.

2. Alrashidi, O., \& Phan, H. (2015). Education context and English teaching and learning in the Kingdom of Saudi Arabia: An overview. English Language Teaching, 8(5), 33.

3. Armbrust, M., Fox, A., Griffith, R., Joseph, A. D., Katz, R., Konwinski, A., Lee, G., Patterson, D., Rabkin, A., Stoica, I., \& Zaharia, M. (2010). A view of cloud computing. Communications of the ACM, 53(4), 50-58.

4. Bhanti, P., Lehri, S., \& Kumar, N. A. R. E. N. D. R. A. (2011). Cloud computing: a new paradigm for data storage in Indian universities. Indian Journal of Computer Science and Engineering (IJCSE), 2(5), 680-683.

5. Chhetri, M. B., Chichin, S., Vo, Q., \& Kowalczyk, R. (2015). Smart CloudBench-A framework for evaluating cloud infrastructure performance. Information Systems Frontiers, 18(3), 413-428.

6. Deloitte. 2017. National Transformation in the Middle East A Digital Journey. [ONLINE] Available at: goo.gl/x8XHPq. [Accessed 1 March 2018].

7. Dikaiakos, M. D., Katsaros, D., Mehra, P., Pallis, G., \& Vakali, A. (2009). Cloud computing: Distributed internet computing for IT and scientific research. IEEE Internet computing, 13(5)

8. Irani, Z., \& Love, P. E. D. (2008). Information systems evaluation: A crisis of understanding. In Z. Irani \& P. E. D. Love (Eds.), Evaluating information systems: Public and private sector (1st ed., p. 20). UK: Butterworth-Heinemann.

9. Lee, M., Wan, C. D., \& Sirat, M. (2017). Hybrid Universities in Malaysia. Studies in Higher Education, 42(10), 1870-1886.

10. Legris, P., Ingham, J., \& Collerette, P. (2003). Why do people use information technology? A critical review of the technology acceptance model. Information Management, 40(3), 191204. 
11. Luftman, J., \& Ben-Zvi, T. (2011). Key issues for it executives 2011: Cautious optimism in uncertain economic times. MIS Quarterly Executive, 10(4), 203-212.

12. Marinescu, D. C. (2013). Cloud computing: theory and practice. 1st ed. Amsterdam: Elsevier Science.

13. Mell, P., \& Grance, T. (2011). The NIST definition of cloud computing.

14. Ministry of Education. (2014). Statistical reports. Retrieved October 15, 2014, from https://www.moe.gov.sa/Arabic/Ministry/Pages/Statistical-reports.aspx.

15. Molly Lee, Morshidi Sirat, Chang Da Wan, (2017) "The development of Malaysian universities: Exploring characteristics emerHEng from interaction between Western academic models and traditional and local cultures", Higher Education Evaluation and Development, Vol. 11 Issue: 1, pp.25-37, https://doi.org/10.1108/HEED-08-2017-004.

16. Rajan, S., \& Jairath, A. (2011, June). Cloud computing: The fifth generation of computing. In Communication Systems and Network Technologies (CSNT), 2011 International Conference on (pp. 665-667). IEEE

17. Saqer A, 2016 Higher Education Management in Saudi Arabia: A Case Study of the University of Business and Technology (UBT)

18. Singh H.P., Bhisikar Arvind and Singh Jitendra, "Innovative ICT Through Cloud Computing", The IUP Journal of Computer Sciences, Vol. VII, No. 1, pp. 37-52, 2013.

19. Sultan, N. (2014). Making use of cloud computing for healthcare provision: Opportunities and challenges. International Journal of Information Management, 34(2), 177-184.

20. Trkman, P., \& Desouza, C. K. (2012). Knowledge risks in organizational networks: An exploratory framework. Journal of Strategic Information Systems, 21(1), 1-17.

21. urRahman, M. M., \& Alhaisoni, E. (2013). Teaching English in Saudi Arabia: Prospects and challenges. Academic Research International, 4(1), 112-118. Retrieved from http://search.proquest.com/docview/ 1352809310?accountid=17227

22. Wyld, D. C. (2009). Moving to the cloud: An introduction to cloud computing in government. Washington DC: IBM Center for the Business of Government.

23. $\mathrm{Xu}, \mathrm{H}$. (2012). Information technology, public administration and citizen participation: The impacts of e-government on political and administrative processes. Public Administration Review, 72(6), 915-920.

24. Yesser. 2018. Maturity Index of Digital Government Services. [ONLINE] Available at: https://www.yesser.gov.sa/AR/Transformation_Indicators/maturity_indicator/Documents/ne w_report.pdf. [Accessed 4 February 2018].

25. Zissis, D., \& Lekkas, D. (2011). Securing e-Government and e-Voting with an open cloud computing architecture. Government Information Quarterly, 28(2), 239-251. 